\title{
O ENSINO TÉCNICO FEDERAL BRASILEIRO NO LIMIAR DA NOVA REPÚBLICA: CAMINHOS DO PROTEC
}

\author{
K. S. QUEIROZ ${ }^{*}$ e F. C. S. SOUZA \\ Instituto Federal de Educação, Ciência e Tecnologia do Rio Grande de Norte \\ karlasqueiroz@gmail.com*
}

Submetido 11/03/2017 - Aceito 27/08/2017

DOI: $10.15628 /$ holos.2017.5771

\begin{abstract}
RESUMO
Em meio ao processo de institucionalização da Nova República, o Ensino Técnico Federal Brasileiro recebeu atenção especial no I Plano Nacional de Desenvolvimento para os anos de 1986-1989, e posteriormente com a criação do Programa de Expansão e Melhoria do Ensino Técnico (PROTEC), lançado em 1986, durante o governo José Sarney. Este programa apresentava como meta a implantação de duzentas escolas técnicas e agrotécnicas no Brasil, objetivando a interiorização do ensino técnico em íntima relação com o processo de industrialização e desenvolvimento regional e nacional, bem como o aprimoramento tecnológico. $\mathrm{O}$ artigo aqui apresentado contempla parte de uma pesquisa de mestrado, ligada ao Programa de Pós-Graduação em Educação Profissional do Instituto Federal de Educação, Ciência e Tecnologia do Rio Grande do Norte, e objetiva promover uma análise
\end{abstract}

acerca do PROTEC, o qual deu origem à primeira expansão Educação Profissional Federal no Rio Grande do Norte. O estudo configura-se como uma pesquisa de base documental e bibliográfica, em que lançaremos mão de documentos oficiais referentes ao PROTEC, produzidos pelo governo federal à época, como também utilizaremos a literatura disponível, ancorada especialmente em Frigotto, Franco e Magalhães (2006) e Cunha (2005). A partir dessa análise identificamos que o PROTEC configura-se como uma peça fundamental para o sucesso do projeto de desenvolvimento econômico do país, haja vista a intensão de expandir essa modalidade de ensino, corriqueiramente voltada para atender às necessidades do mercado de trabalho. A análise também evidenciou no PROTEC uma perspectiva tecnicista e produtivista de educação, além da marca clientelista e influências da Teoria do Capital Humano.

PALAVRAS-CHAVE: Ensino Técnico, Desenvolvimento Econômico, PROTEC, Teoria do Capital Humano.

\section{THE BRAZILIAN FEDERAL TECHNICAL TEACHING IN THE THRESHOLD OF THE NEW REPUBLIC: PROTEC PATHWAYS}

\section{ABSTRACT}

In the midst of the process of institutionalization of the New Republic, the Brazilian Federal Technical Education received special attention in the First National Development Plan (1986-1989), and later with the creation of the Program for Expansion and Improvement of Technical Education (PROTEC), 1986. This program aimed at the implementation of two hundred technical and agrotechnical schools in Brazil, aiming at internalizing technical education in close relation with the process of industrialization and regional and national development, as well as technological improvement. The article presented here includes part of a master's research, linked to the Post-Graduation Program in Professional Education of the Federal Institute of Education, Science and Technology of Rio Grande do Norte, and aims to promote an analysis about PROTEC, which originated the first Federal Professional Education expansion in Rio Grande do
Norte. The study is a documentary and bibliographical research, in which we will use official documents related to PROTEC, as well as the available literature, especially anchored in Frigotto, Franco and Magalhães (2006) and Cunha (2005). Based on this analysis, we have identified that PROTEC is a key element for the success of the country's economic development project, given the intention of expanding this type of education, which is Usually geared towards meeting the needs of the market. The analysis also highlighted in PROTEC a technicist and productivist perspective of education, as well as the clientelistic brand and influences of Human Capital Theory.

KEYWORDS: Technical Teaching, Economic Development, PROTEC, Theory of Human Capital 


\section{INTRODUÇÃO}

A análise acerca do Ensino Técnico Federal no Brasil nos mostra que esta modalidade de ensino sempre apresentou estreitos laços com os projetos de desenvolvimento econômico do país, alicerçados no processo de industrialização. Criado para ser um instrumento de satisfação das necessidades do mercado de trabalho, desde sua primeira iniciativa, ainda na Primeira República, com as Escolas de Aprendizes Artífices, o Ensino Técnico perpetuou essa marca ao longo dos anos, não sendo diferente sua apresentação com a deflagração da Nova República.

Sob a presidência de José Sarney (1985-1990), a estratégia de desenvolvimento econômico para o Brasil dos primeiros anos da Nova República, foi projetada no I Plano Nacional de Desenvolvimento (PND) para os anos de 1986 a 1989. No bojo da execução deste Plano foram traçadas, entre outras ações, os caminhos a serem seguidos pela política educacional, enquanto partícipe do eixo de desenvolvimento social. No campo da educação, o Ensino técnico ganhou destaque especial no plano, materializado meses depois com o lançamento do Programa de Expansão e Melhoria de Ensino Técnico (PROTEC), tema central deste estudo.

Dessa forma, o objetivo deste artigo é realizar uma analisar acerca desse programa, o qual deu origem a Primeira Expansão da Rede Federal de Educação Profissional, compreendida como um instrumento para a execução de uma proposta de crescimento econômico vigente nos anos 1980.

Enquanto parte integrante de nossa pesquisa de mestrado ainda em curso, vinculada ao Programa de Pós-Graduação em Educação Profissional (PPGEP), do Instituto Federal de Educação, Ciência e Tecnologia do Rio Grande do Norte (IFRN), o trabalho que ora apresentamos, aponta dados que compõem a construção do contexto nacional da Educação Profissional dos primeiros anos da Nova República, e tem como recursos metodológicos uma pesquisa bibliográfica e documental, com base nos documentos oficiais, produzidos pelo governo federal à época, bem como a literatura disponível para realizarmos a análise do programa.

Em um primeiro momento, discutiremos de forma breve o I Plano Nacional de Desenvolvimento e seu foco no crescimento econômico e posteriormente realizaremos a análise sobre o PROTEC, tomando como referência os estudos de Frigotto, Franco e Magalhães (2006) e Cunha (2005).

\section{O ENSINO TÉCNICO NA NOVA REPÚBLICA: CAMINHOS DO I PLANO NACIONAL DE DESENVOLVIMENTO}

Com o fim do regime civil-militar, em 1985, o país conduz à presidência, através de eleições indiretas, o candidato Tancredo Neves, marcando o que seria o início do processo de transição política para a Nova República. Impossibilitado de iniciar seu mandato em função de sua morte, assume o cargo o vice-presidente José Sarney.

O novo contexto nacional impunha à Nova República, segundo Brum (2003), dois grandes desafios a serem vencidos: o de implantar o Estado de direito democrático e o de definir um 
novo projeto de desenvolvimento para alavancar a expansão econômica e corrigir e promover o equilíbrio social.

Norteado por tais desafios, o governo lança, em 06 de junho de 1986, por meio da Lei no 7.486, o I Plano Nacional de Desenvolvimento (PND) pautado em três metas estratégicas: a implantação de um plano de reforma, combate à pobreza e crescimento econômico.

De acordo com o disposto no documento (BRASIL, 1986), esse projeto de governo tinha como objetivo um amplo enxugamento da máquina pública, restringindo as atividades do Estado à prestação de serviços essenciais, redução dos gastos públicos, descentralização das atribuições e recursos para os estados e municípios, privatizações, democratização do capital das empresas estatais, bem como a renegociação da dívida externa, a redução da inflação e o apoio financeiro ao capital privado.

No que diz respeito ao combate à pobreza, a atuação governamental estaria direcionada no sentido de uma melhor distribuição de renda, por meio da valorização salarial e concentração de esforços e recursos financeiros para execução de programas sociais voltados para a redução dos problemas nas áreas de saúde, alimentação e habitação.

Coube à iniciativa privada o desenvolvimento das atividades produtivas que viriam a alavancar o crescimento econômico. Esse novo ciclo de expansão industrial estava fundamentado em um padrão de industrialização que tinha como questão central a introdução de novas tecnologias que proporcionassem maior competitividade no plano internacional e ampliação do mercado interno.

Assim, a indústria nacional, instalada ao longo das três fases do processo de substituição de importações, sem dúvidas foi de extrema importância para a composição da base industrial do país, oferecendo certa solidez ao setor. Entretanto, como nos mostra Brum (2002, p. 426), o Brasil experimentou, nos anos de 1980, o que se pode chamar de esgotamento da matriz industrial.

[...] a substituição de importações já não tinha mais o dinamismo suficiente para continuar a ser o carro chefe da expansão industrial e econômica do país. Desde então, a sustentação do avanço da industrialização brasileira passou a depender da definição de uma nova matriz industrial.

O desafio que se colocava ao setor industrial era o desenvolvimento consistente de tecnologia de ponta para superar o atraso proporcionado por anos de incipientes investimentos científicos e tecnológicos, como também em educação e formação de recursos humanos.

Para vencer a obsolescência tecnológica, as estratégias expressas no I PND estavam direcionadas para o estabelecimento de redes de criação tecnológica que integrassem centros de pesquisas, universidades e indústrias, para expandir e transferir os avanços alcançados para o setor de produção.

O texto do I PND buscava enfatizar que o novo projeto de crescimento econômico apresentava como diferencial a orientação social que lhe foi dado, rendendo assim uma série de avaliações e projeção de ações no âmbito do desenvolvimento social. Entre elas, a formação de recursos humanos também recebeu destaque especial na análise da questão educacional em 
seus vários níveis e modalidades de ensino e as linhas programáticas de cada um. No item 2.2 denominado, Programa Melhoria do Ensino de 20 Grau (BRASIL, 1986, p. 66), definiu-se que:

As escolas técnicas federais de 20 grau - industriais e agrícolas - receberão recursos necessários ao reforço e à ampliação de sua capacidade de atendimento, de tal forma que diversifiquem a oferta de habilitações, estendendo-as, tanto quanto possível ao setor de serviços modernos.

Para levar a cabo os objetivos básicos aos quais o governo se propunha para o setor da educação, especialmente no âmbito do ensino de 20 grau profissional, o governo ampara-se na Exposição de Motivos no 56, de 24 de fevereiro de 1986, publicada no Diário Oficial da União de 26 de fevereiro de 1986, e na Exposição de Motivos no 135, de 4 de julho de 1986, publicada no Diário Oficial da União de 07 de julho de 1984, que tratam respectivamente da implementação e obtenção dos recursos humanos necessários ao funcionamento das escolas, e lança, em 04 de julho de 1986, o Programa de Expansão e Melhoria de Ensino Técnico (PROTEC), tema central desse trabalho.

\section{ESTRATÉGIA DE EXPANSÃO DO ENSINO TÉCNICO: A CRIAÇÃO DO PROTEC}

Justificado no documento oficial de lançamento, com base nas alegações de que o ensino técnico deveriam atender tanto às demandas provenientes da expansão e modernização da indústria, agricultura e serviços, como também ao que chamou de "reclamos da população jovem por ensino técnico" (SARNEY, 1986, p. 412), que possibilitasse seu ingresso no mercado de trabalho e participação social, o Programa de Expansão e Melhoria de Ensino Técnico previa a implantação de duzentas escolas técnicas industriais e agrotécnicas em todo o Brasil, dando prioridade às cidades dos interiores dos estados brasileiros, para atender às necessidades do processo de industrialização e possibilitar a formação de profissionais qualificados para o campo, norteados pela política de modernização e justiça social.

De acordo com o documento BRASIL (1994, p. 56), o PROTEC apresentava como objetivos:

[...] promover a expansão e melhoria do ensino técnico, de acordo com as necessidades do mundo do trabalho em processo de expansão e diversificação, através da implantação de novas escolas em regiões desassistidas e do apoio a instituições de ensino já existentes, possibilitando a universalização de ofertas de habilitações profissionais e também a pré-qualificação em agropecuária em nível do ensino fundamental.

Os estudos de Cunha (2005), também ratificados por Frigotto, Franco e Magalhães (2006), entretanto, indicam que a motivação na qual se firmou a implantação do PROTEC, na verdade, não era tão nobre. Segundo esses autores a intencionalidade para a criação do programa estava ligada a interesses mais políticos que técnicos e sociais, ficando explícito o critério clientelista em que foi edificado. Na prática, essa investida se configurou como uma estratégia para fazer frente à política educacional de Leonel Brizola, então governador do estado do Rio de Janeiro e concorrente de peso à presidência da república. Este governador definiu o estabelecimento de quinhentos prédios para escolas de 1 으 grau para o ensino integral - os Centros Integrados de 
Educação Pública (CIEPs), fato que the trouxe grande popularidade. Nessa perspectiva, as duzentas Escolas Técnicas Federais se sobrepunham aos CIEPS em função de seu preço, extensão e valor social. As Escolas Técnicas Federais seriam mais caras e estariam em todos os estados da federação.

A orientação de distribuição dessas duzentas escolas também denota a existência de critérios clientelistas. Mesmo que os objetivos expressos no programa seguissem uma tendência de interiorização, em consonância com a proposta de descentralização regional da capacidade produtiva, conforme definido para o novo padrão de industrialização elaborado no I PND, foi percebida uma prática corriqueira de distribuição dessas instituições em localidades com insuficiente ou inexistente desenvolvimento industrial, sendo levados em consideração, pedidos de diversos políticos que chegavam em grande quantidade ao Ministério da Educação (MEC).

Além de apresentar a proposta de expansão do ensino técnico como suporte em atenção ao mercado de trabalho, também estava delegado à essas escolas, o domínio efetivo da técnica e o aprimoramento dos processos tecnológicos, o que revela a concepção produtivista e tecnicista de educação implantada por meio do PROTEC.

A ideia produtivista aqui expressa se insere na perspectiva da centralidade no mercado, que nada mais é que o próprio sistema de produção capitalista. Partindo do princípio de que as relações sociais são definidas por meio do modo de produção que se estabelece em sociedade, o capital assume sua forma dominante promovendo seus próprios interesses em todas as esferas, não sendo diferente sua interferência nas determinações do sistema educacional e em especial na Educação Profissional. Logo, como relata Frigotto, Franco e Magalhães (2006, p. 140), "o grande e fundamental educador é o capital, disfarçado sob a categoria mercado de trabalho".

Sendo o ensino técnico elaborado para satisfazer aos interesses do mercado de trabalho, em outras palavras, do próprio capital, o que estava em pauta não era a organização do sistema educacional para suprir as necessidades da sociedade enquanto coletivo humano, mas sim a organização e satisfação do sistema econômico, através da capacitação de recursos humanos, ou classe trabalhadora objetivando o aumento da produtividade e da maximização do lucro.

O caráter tecnicista empreendido ao PROTEC estava impresso na íntima associação do ensino técnico com o desenvolvimento. Publicizado no documento de lançamento como "fator de primeira grandeza para o desenvolvimento nacional" e "instrumento fundamental à melhoria da produtividade nacional" (BRASIL,1986, p. 414), o ensino técnico deveria ser produtor de tecnologia para que o país pudesse progredir, o que supunha assim a necessidade de massificação, ampliação desse ensino.

Segundo Frigotto, Franco e Magalhães (2006), de fato havia uma demanda por formação técnica a ser resolvida, porém não sob os moldes do paradigma taylorista-fordista de organização do trabalho e qualificação técnica inscritos no programa. De acordo com este paradigma, o progresso da ciência e da tecnologia traziam como necessidade a generalizada qualificação da mão-de-obra, ao passo que possibilitaria a ampliação da oferta de emprego, aproximando ao pleno emprego, ou seja, gozando de direitos trabalhistas legalmente adquiridos. 
Entretanto, o que se evidenciava mundialmente, inclusive no Brasil, era o desenho de um novo formato de organização do processo produtivo, que flexibiliza as relações promovendo uma redução dos postos de trabalho e a formação de mão-de-obra excedente, denominado acumulação flexível. Também são características desse sistema de acumulação a reorganização política e social do Estado com a adesão as políticas neoliberais de enxugamento da intervenção estatal no âmbito social, privatização, descentralização e focalização impostas pelos organismos internacionais. Dessa forma, eram perceptíveis os indícios de que o modelo de ensino técnico pensado na perspectiva da formação de força de trabalho em massa estava desconectado da nova ordem estabelecida.

O novo contexto neoliberal e de acumulação flexível se manifesta no campo da educação sob a exigência de uma qualificação não apenas técnica, mas que pudesse oferecer, como sinaliza Frigotto, Franco e Magalhães (2006, p. 145), "uma formação mais complexa, abstratas e polivalentes, para formar trabalhadores subordinados aos interesses do capital". Assim, estavam postas as novas condições para a reintrodução da velha conhecida Teoria do Capital Humano.

Sistematizada pelo economista Teodoro Schultz, nos anos 1950, esta teoria surge como um desdobramento da teoria do desenvolvimento econômico. Sua tese central explicava que, além do capital físico - maquinaria - e trabalho, existia um outro elemento essencial para alcançar a compreensão do crescimento da economia. Este fator poderia ser atribuído ao investimento nos indivíduos, ou no capital humano.

O conceito de capital humano, segundo Frigotto (1984, p. 41) faz referência ao:

[...] montante de investimento que uma nação faz ou os indivíduos fazem, na expectativa de retornos adicionais futuros. Do ponto de vista macroeconômico, o investimento no "fator humano" passa a significar um dos determinantes básicos para aumento da produtividade e elemento de superação do atraso econômico. Do ponto de vista microeconômico, constitui-se no fator explicativo das diferenças individuais de produtividade e de renda e, consequentemente, de mobilidade social.

A educação passa assim a ser considerada como um instrumento do desenvolvimento econômico, distribuição de renda e equalização social. Conforme observa Frigotto (1984), essa teoria é forjada no seio da disputa entre as classes sociais - burguesia e trabalhadores - e se desenvolve por meio e em benefício dos interesses do capital, sendo disseminada ideologicamente para encobrir a realidade do processo de acumulação e concentração de renda, imprescindíveis à manutenção das relações capitalistas.

Para Frigotto (1986, p. 224), as instituições escolares se tornam instrumentos a serviço do capital em virtude de sua incompetência, a saber:

Sua improdutividade, dentro das relações capitalistas de produção, torna-se produtiva. Na medida em que a escola é desqualificada para a classe dominada, para os filhos dos trabalhadores, ela cumpre, ao mesmo tempo, uma dupla função na reprodução das relações capitalistas de produção: justifica a situação de explorados e, ao impedir o acesso ao saber elaborado, limita a classe trabalhadora na sua luta contra o capital. 
No que tange a execução do PROTEC, são identificadas duas modalidades de atuação que seriam executadas no ensino de 10 e 20 grau, que são: construção das escolas e instalação de equipamento pelo MEC. Na prática, o programa se materializou de maneira diferente da ideia veiculada oficialmente no programa. Não houve a implantação/construção de duzentas Escolas Técnicas Industriais e Agrícolas, mas, como denominou Cunha (2005), de fato seriam realizados duzentos convênios, beneficiando escolas já existentes e construção de novas estruturas. 0 primeiro ano de execução dedicado basicamente a recuperação das já existentes, denunciando também um caráter obreirista impresso no programa.

Quanto a construção das novas escolas, importa ressaltar que o MEC se viu obrigado a reconsiderar sua meta audaciosa e a formatação inicialmente planejada. Para tanto, criou, por meio da Portaria № 67, de 09 de fevereiro de 1987, um sistema de escolas técnicas no formato de Unidades de Ensino Descentralizadas (UNEDs), equivalente aos campi universitários.

As UNEDs, como o próprio nome sugere, eram unidades descentralizadas, seu quadro de funcionários e estrutura física seriam reduzidos e não iriam dispor de responsabilidades com setor de compras, patrimônio, contabilidade, orçamento, sistema financeiro, entre outras. Estas atividades seriam desenvolvidas pelas Escolas Técnicas Federais ou CEFETs, aos quais as UNEDs estivessem ligadas. Tal proposta seria menos onerosa aos cofres públicos e proporcionaria a criação de 66,3 mil novas vagas (BRASIL, 1990. p. 14). Vale mencionar que a instalação das UNEDs exigia uma contrapartida dos municípios beneficiados com a nova escola, o que geralmente se configurava na doação do terreno para construção do prédio

Ao final de seu mandato, como mostra o documento Realizações do Ministério da Educação, Período de 85/90, do Governo Sarney (BRASIL, 1990), identificamos o seguinte cenário: das 77 escolas agrícolas de 10 grau, 46 estavam em funcionamento, embora ainda não concluídas; 22 estavam em andamento; 5 apresentavam obras paralisadas; 1 aguardava recursos e 3 estavam em estudo.

Ainda com base no mesmo documento, no que diz respeito às escolas de 20 grau, industriais e agrotécnicas, o panorama era o seguinte: das 26 escolas agrotécnicas projetadas, 2 estavam em funcionamento, 7 em execução, 3 em licitação, 11 a licitar e 3 em estudo. Já as escolas industriais, das 64 projetadas, 8 estavam concluídas, 7 em conclusão, 19 em execução, 8 em licitação, 18 a licitar e 4 em estudo.

Da audaciosa proposta inicial de criação de duzentas escolas para o atendimento do ensino técnico, pouco foi de fato executado. A escassez de recursos, observada nos relatórios oficiais estendia-se não apenas na etapa da construção das escolas mas também na sua estruturação de quadro de servidores, visto que foram criados os Decretos no 95.682 e Decreto no 95.683, ambos de 28 de janeiro de 1988, relativos a contenção de despesas e proibição de contratação de servidores, docentes e técnicos administrativos. Tais evidência constatam que o PROTEC enfrentava dificuldades importantes na sua execução, embora tenha se mantido em governos posteriores, porém não enquanto programa prioritário, como no governo de sua criação. 


\section{CONSIDERAÇÕES FINAIS}

Forjado em meio ao processo de redemocratização da nação, com fortes influências da política neoliberal e do inovador sistema de acumulação flexível, o PROTEC foi criado como parte integrante de um projeto de desenvolvimento econômico do país, em que a proposta educacional para o ensino técnico manteve uma cultura já estabelecida de atuar no sentido de atender as necessidades do mercado de trabalho, ou em outras palavras, do sistema capitalista de produção.

Enquanto programa gestado para essa finalidade de suprir as demandas do capital, foi possível identificar que o PROTEC configura-se como uma peça fundamental para o sucesso do projeto de crescimento econômico do país, haja vista a intensão de expandir essa modalidade de ensino, em que foi impressa uma perspectiva tecnicista e produtivista de educação na sua concepção, bem como um marcante viés clientelista e obreirista na intencionalidade e execução do programa.

Também é pertinente ressaltar que o PROTEC recebe forte influência da Teoria do Capital Humano, que percebe a educação como um instrumento a serviço dos interesses do capital, nesse novo contexto tendo como mentores, organismos como o Banco Mundial, Banco Interamericano de Desenvolvimento (BID), Organização das Nações Unidas para a Educação, Ciência e Cultura (UNESCO), Organização Internacional do Trabalho (OIT), mantendo a educação enquanto peça estratégica do grande capital.

\section{REFERÊNCIAS}

Decreto no. 95.682, de 28 de janeiro de 1988. Dispõe sobre medidas de contenção de despesas nos órgãos e entidades da Administração Federal, e dá outras providências. Recuperado de http://www.planalto.gov.br/ccivil_03/decreto/Antigos/D95682.htm.

Decreto no. 95.683, de 28 de janeiro de 1988. Estabelece normas complementares ao Regulamento da Lei $n^{\circ} 7.596$, de 10 de abril de 1987, e dá outras providências. Recuperado de http://www.planalto.gov.br/ccivil_03/decreto/antigos/D95683.htm.

Exposição de Motivos no 56, de 24 de fevereiro de 1986. Implementação de um Programa de expansão e melhoria do ensino de 2o grau, nos termos da presente Exposição de Motivos. Recuperado em http://www.jusbrasil.com.br/diarios/3218019/dou-secao-1-26-02-1986-pg4/pdfView.

Exposição de Motivos no 135, de 4 de julho de 1986. Elenco de medidas no âmbito do Programa de Expansão e Melhoria do Ensino Técnico, a serem desenvolvidas em conjunto com o Ministério Extraordinário para Assuntos de Administração, com vistas à consecução dos recursos humanos necessários ao funcionamento das escolas, nos termos da presente Exposição de Motivos. DOU de 07/07/1986, seção II, p. 3458. Recuperado em http://www.jusbrasil.com.br/diarios/3529371/dou-secao-2-07-07-1986-pg-2/pdfView.

BRASIL. Lei no. 7.486, de 6 de junho de 1986. Aprova as diretrizes do Primeiro Plano Nacional de Desenvolvimento (PND) da Nova República, para o período de 1886 a 1989. Recuperado em http://www.planalto.gov.br/ccivil_03/leis/1980-1988/L7486.htm. 
Ministério da Educação. (1990). Realizações do Ministério da Educação período: 85/90 - Governo José Sarney. Brasília: MEC. Recuperado em http://www.dominiopublico.gov.br/download/texto/me002550.pdf.

Portaria no 67, de 6 de fevereiro de 1987. Cria Unidades de Ensino Descentralizadas. Recuperado de http://www.jusbrasil.com.br/diarios/3196334/dou-secao-1-10-02-1987-pg18/pdfView>DOU de 10/02/1987, Seção I, p. 2062.

BRUM, A. J. (2005). Desenvolvimento econômico brasileiro (24a ed.) Petrópolis: Vozes.

CUNHA, L. A. (2005) O ensino profissional na irradiação do industrialismo. São Paulo: UNESP.

FRIGOTTO, G., FRANCO, M. A. C., MAGALHÃES, A. L. (2006). Programa de Melhoria e Expansão do Ensino Técnico: expressão de um conflito de concepções de educação tecnológica. In F., G., Franco, M. C. (Org.), A formação do cidadão produtivo: a cultura de mercado no ensino médio técnico (pp. 139-149). Brasília: Instituto Nacional de Estudos e Pesquisas Educacionais Anísio Teixeira.

FRIGOTTO, G. (1984) A produtividade da escola improdutiva (2a ed.). São Paulo: Cortez.

Lançamento do Programa de Expansão e Melhoria do Ensino Técnico. (1986). A palavra do Presidente: discursos e mensagens. Brasília: Presidência da República, Recuperado em: http://www.biblioteca.presidencia.gov.br/expresidentes/josesarney/discursos/1986/79.pdf/at_download/file.

SCHULTZ, T. (1973) O capital humano: investimento em educação e pesquisa. Trad. de Marco Aurélio de M. Matos. Rio de Janeiro: Zahar. 